\title{
Heart valve replacement in children
}

\author{
BER N A R O VID NE, MOR R IS J LEVY \\ Thoracic-cardiovascular Surgery Department, Beilinson Hospital, Petah-Tiqva, and \\ University of Tel-Aviv Medical School, Israel
}

\begin{abstract}
Twenty children with heart valve disease were operated upon and underwent heart valve replacement between 1965 and 1968. Thirteen were girls and seven boys. At the time of operation their ages ranged from 3 to 16 years. All the patients were in classes III or IV prior to operation. Three children suffered from congenital valvular lesions and 17 from rheumatic lesions. In each patient left and/or right heart catheterization and angiographic studies were performed. Six patients underwent aortic valve replacement, 11 mitral, 1 tricuspid, and 2 double valve replacement. Mitral annuloplasty was performed in addition to aortic valve replacement in two patients, and tricuspid annuloplasty in addition to mitral valve replacement in another patient. In 19 patients a prosthetic valve was used and in one an aortic heterograft (pig). Two patients died in the early postoperative period $(10 \%)$, and two later, two and nine months after surgery $(10 \%)$. Postoperative thromboembolism occurred in four patients $(20 \%)$. All have completely recovered. All the surviving 16 patients have been followed for a period of one to four and a half years and all showed significant clinical improvement; all children of school age have returned to school and/or other normal actitivies. The overall result has been encouraging and might justify a more aggressive approach in the management of valvular diseases in this specific group of patients.
\end{abstract}

Artificial cardiac valves are now widely accepted in the surgical treatment of acquired valvular heart disease in adults. Despite the satisfactory results in adult patients there has been an understandable reluctance to extend the same criteria to the paediatric group. This fear is justifiable, since long-term follow-up studies on the durability and continued competence of valve prostheses are not available.

Despite this disadvantage, in some children whose valves have been damaged to such a degree that medical treatment is no longer effective, heart valve replacement becomes the only possible treatment. Recent advances have been made toward the construction of smaller prostheses which may be safely implanted in small hearts and still not become inadequate as the patient grows.

This report is an evaluation of a series of 20 patients, 3 to 16 years of age, who have had mitral, aortic, tricuspid or combined valve replacement in the last four and a half years.

\section{MATERIAL}

Young patients were selected for replacement of valves only when no other satisfactory means of surgical treatment was available. A total of 20 patients, 3 to 16 years of age, were operated upon and underwent heart valve replacement between 1965 and 1968 (Fig. 1). Thirteen were boys and seven girls. The aetiology of the lesions is shown in Table I, the majority being rheumatic. Seventeen patients presented a history of rheumatic fever. Among them the interval between the rheumatic fever and the cardiac symptoms varied from 20 months to 7 years, with an average of 39 months. The functional capacity prior to surgery is plotted in Figure 2.

Episodes of congestive cardiac failure had occurred or were present at the time of examination in every

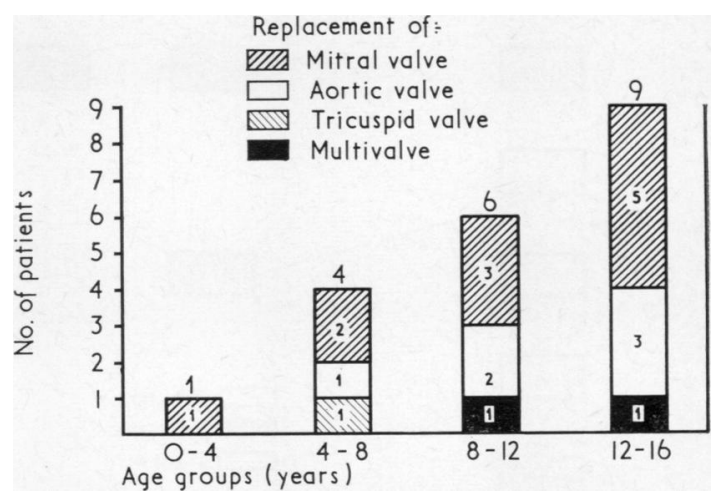

FIG. 1. Age distribution of 20 children and adolescents submitted to heart valve replacement. 
T A B L E I

AETIOLOGY OF VALVULAR LESIONS

\begin{tabular}{cc|c|c|c|c}
\hline \multicolumn{1}{c|}{ Lesion } & Aortic & Mitral & Tricuspid & $\begin{array}{c}\text { Multi- } \\
\text { valvular }\end{array}$ \\
\hline \begin{tabular}{cc|c} 
Rheumatic \\
Congenital
\end{tabular} & $\ldots$ & 5 & 10 & 1 & 2 \\
\hline Total & 1 & 1 & 1 & 2 \\
\hline
\end{tabular}

patient. Left and/or right heart catheterization and angiographic studies were performed in all patients.

Six patients underwent aortic valve replacement, 11 mitral, 1 tricuspid, and 2 double valve replacement. Mitral annuloplasty was performed in addition to aortic valve replacement in two patients and tricuspid annuloplasty in addition to mitral valve replacement in another patient.

\section{SURGICAL TECHNIQUE}

All the patients were operated upon with the assistance of cardiopulmonary bypass. using the Rigg disposable oxygenator combined with the single head roller pump. A heat exchange unit was incorporated into the arterial line connected to the Zuhdi water pump.

The whole system was primed with Ringer solution and $5 \%$ dextrose $(1: 1)$. One pint of heparinized blood was used only in patients weighing $15 \mathrm{~kg}$. or less. A

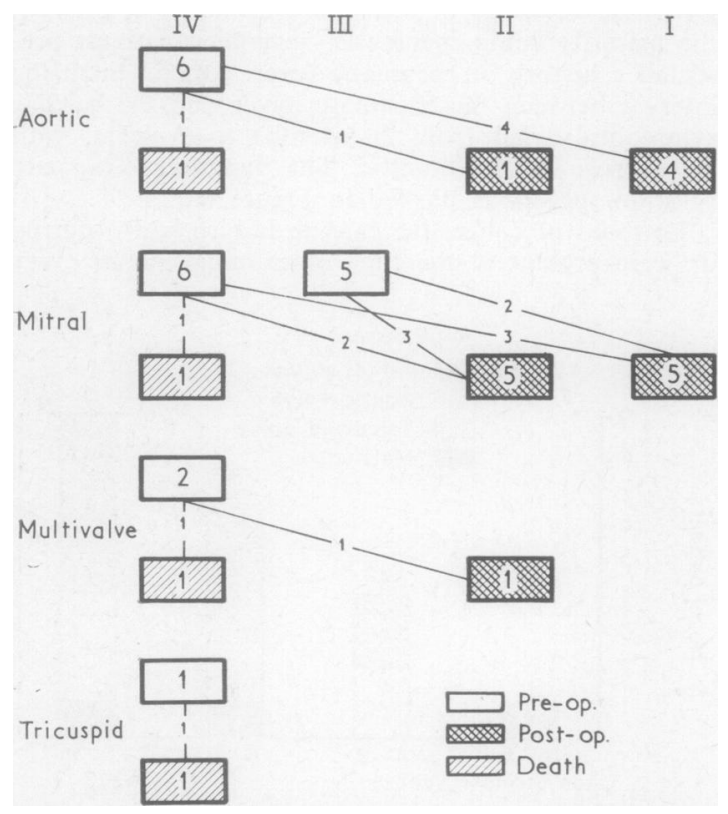

FIG. 2. Pre- and post-operative functional status of patients undergoing uni- or multi-valve replacement.
T A B L E I I

TYPES OF PROSTHESES OR GRAFTS

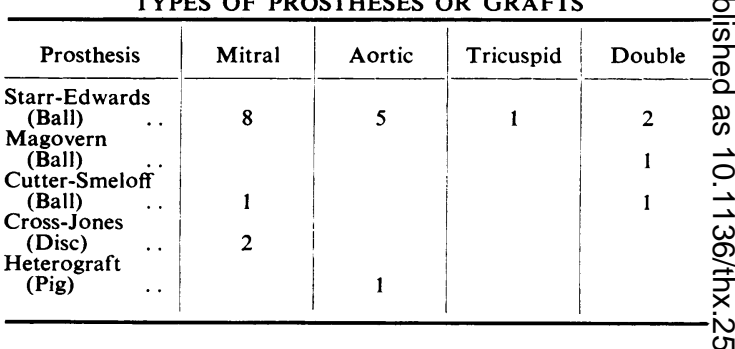

hypothermic level of $30^{\circ} \mathrm{C}$. was maintained during $\overrightarrow{\mathrm{g}}$ the bypass period.

Continuous perfusion of both coronary arteries $\stackrel{\circ}{I}$ whenever possible was done during aortic valve $\vec{c}$ replacement. Electrically induced ventricular fibrilla- פ tion was applied in mitral valve replacement to allow uninterrupted myocardial perfusion and prevent the hazard of an air embolus.

The surgical technique for valve replacement $\vec{\theta}$ (prosthesis or graft) has been previously reported $\bigcirc$ (Levy, Vidne, and Lebinshon, 1969). The type of valve prosthesis used is listed in Table II.

\section{RESULTS}

Two patients died in the early post-operative $\stackrel{\mathbb{Q}}{\varrho}$ period (1 to 30 days after operation), one of them $\overrightarrow{\overrightarrow{0}}$ because of a low output syndrome after an aortic and mitral valve replacement on the third postoperative day. The second had cor bovinum due to mitral, tricuspid, and aortic lesions, and cardiac beats could not be restored at the completion of the procedure. There were two late deaths: the first occurred nine months after tricuspid valve $\frac{5}{3}$ replacement in an 11-year-old girl with Ebstein's anomaly. Although the patient had initiallyo improved following the tricuspid valve replacement, she later developed a leak around the prosthesis with subsequent deterioration. Ten days $\rightarrow$ after a successful repair of the prosthesis insufficiency, the patient developed intractable ventri- $N$ cular tachycardia and fibrillation. The second death occurred in a 16-year-old boy two months after aortic valve replacement by heterograft; hew developed subacute endocarditis after discharge from hospital (Table III).

Post-operative thromboembolism was the main $\bar{\varnothing}$ complication after insertion of heart valve pros-? theses (Vidne and Levy, 1969). This complication occurred in four patients $(20 \%)$, in two after $\stackrel{\vec{\Phi}}{\circ}$ aortic valve replacement and in the other two@ after mitral valve replacement, between two $\stackrel{\mathbb{Q}}{\circ}$ months and two years after operation. All theseo patients have recovered completely and are 
T A B L E I I I

EARLY (WITHIN 30 DAYS) AND LATE MORTALITY IN 20 PATIENTS 16 YEARS OLD OR YOUNGER UNDERGOING UNI- OR MULTI- VALVE REPLACEMENT

\begin{tabular}{|c|c|c|c|c|}
\hline \multirow{2}{*}{\multicolumn{2}{|c|}{ Lesion }} & \multirow{2}{*}{ No. of Patients } & \multicolumn{2}{|c|}{ Mortality } \\
\hline & & & Early & Late \\
\hline $\begin{array}{l}\text { Aortic... } \\
\text { Mitral.. } \\
\text { Tricuspid } \\
\text { Multivalve }\end{array}$ & $\begin{array}{l}. \\
\cdots \\
\ldots\end{array}$ & $\begin{array}{r}6 \\
11 \\
1 \\
2\end{array}$ & $\begin{array}{l}1 \\
1\end{array}$ & $\begin{array}{l}1 \\
1\end{array}$ \\
\hline Total .. & $\ldots$ & 20 & $2(10 \%)$ & $2(10 \%)$ \\
\hline
\end{tabular}

presently asymptomatic. In one of the four patients the episode of thromboembolism occurred when the patient was off anticoagulant therapy.

The present functional capacity for all the surviving 16 patients is shown in Figure 2 . The longest time lapse since operation has been 54 months so far, and the shortest 6 months, with a mean of 27.4 months. All patients improved and returned to normal activity or had only trivial restrictions. A significant decrease in heart size was evident in serial chest radiographs in the majority of patients (Figs 3, 4, and 5). All the patients are still under anticoagulant therapy and are advised to continue for the time being.

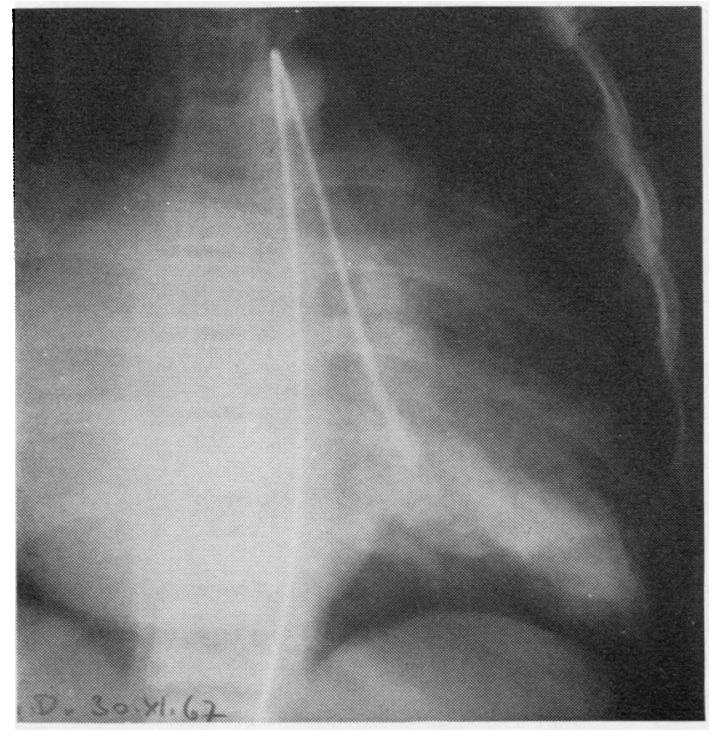

(a)

FIG. 3. A 12-year-old girl with severe mitral insufficiency due to rheumatic fever. (a) Selective ventriculogram indicating severe mitral insufficiency with a giant left atrium. (b) Lateral position of the same.
DISCUSSION

The reliability of the presently available valve prostheses offers many patients with valvular disease the possibility of restoration to normal function (Bloodwell, Hallman, and Cooley, 1968). The fact that the patient's functional capacity has been considerably improved, and also that the cardiac sillhouette has significantly decreased in size after operation, indicates that the prosthesis used was of adequate size and probably will not have to be replaced as the patient grows. Of all the patients in this group, perhaps only one with mitral insufficiency due to Marfan's syndrome, who had been operated on at the age of 3 years, might require a second operation later in life (Fig. 6) (Shahin, Eshkol, and Levy, 1969).

The indication and choice of operation for mitral insufficiency in children and adolescents is usually the same as for adults, namely, if the valvular deformity does not allow reconstruction, valve replacement becomes mandatory (Levy, Varco, Lillehei, and Edwards, 1963). In aortic valve disease, however (excluding congenital aortic stenosis), the only treatment is replacement by prosthesis or graft (Levy et al., 1969). Of

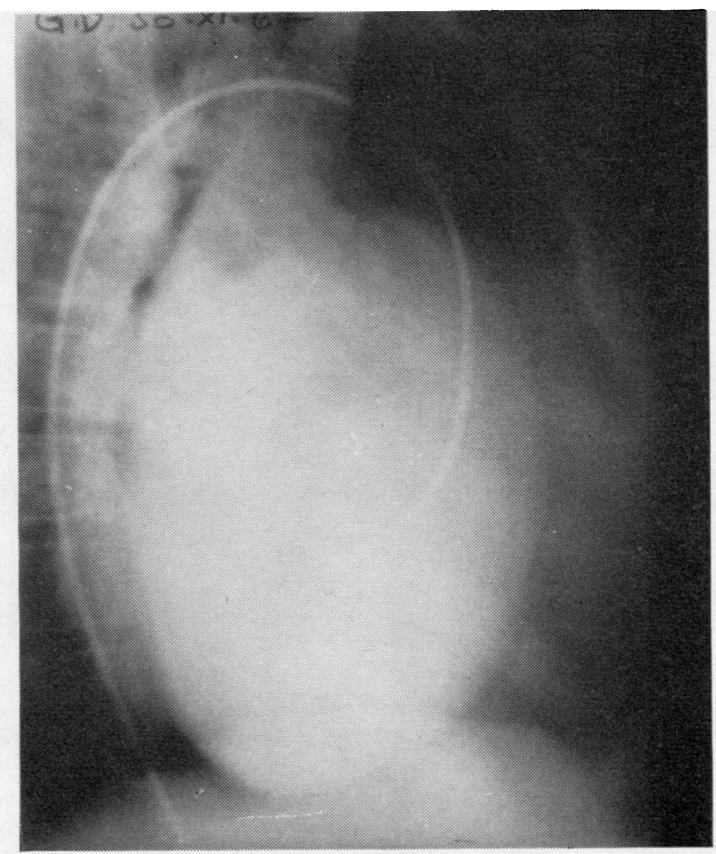

(b) 
FIG. 4. The same patient as in Fig. 3: Pre-operative (a) and post-operative (b) chest radiographs 9 months after surgery, illustrating significant reduction of the heart's size and left atrium. The Starr-Edwards ball valve has been inserted to correct the mitral insufficiency.

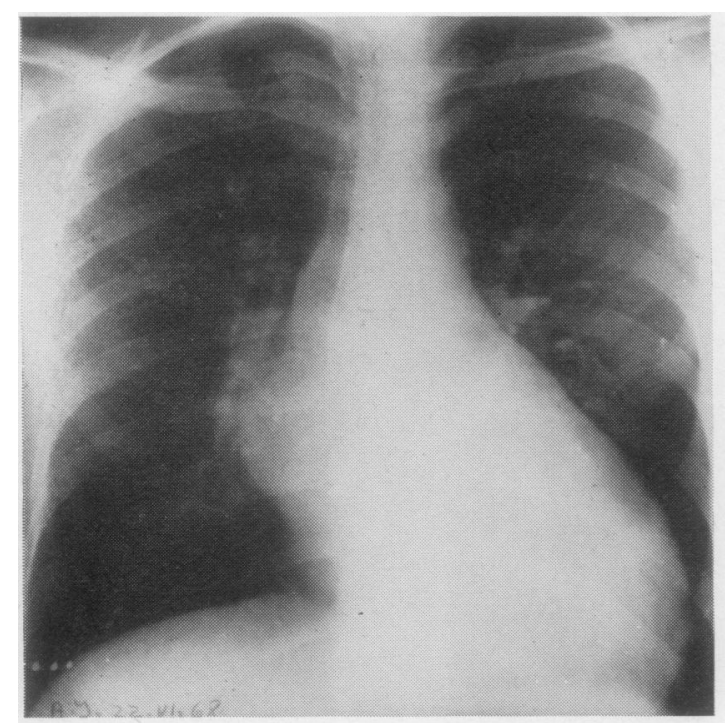

(a)

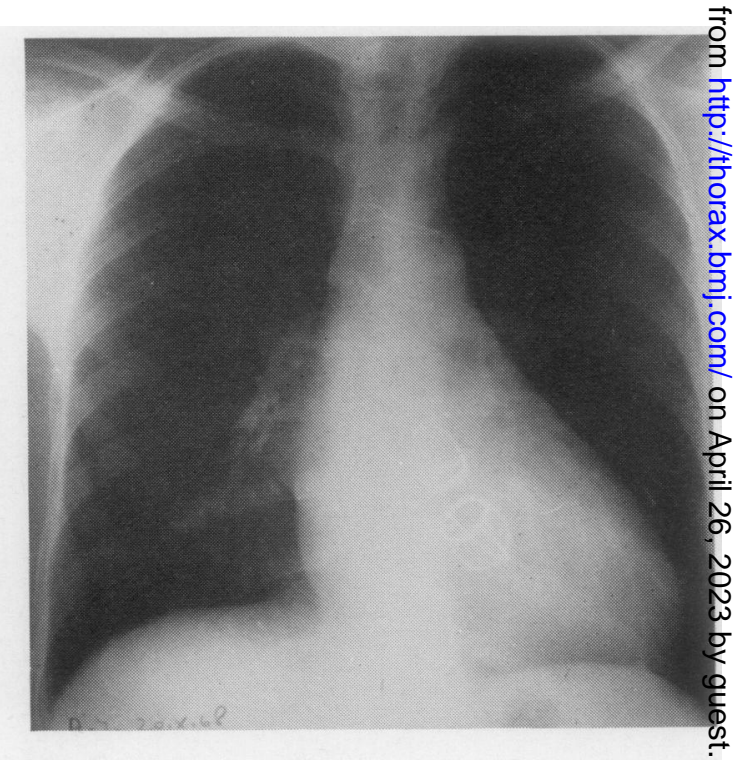

(b)

FIG. 5. Chest radiographs of a 16-year-old boy suffering from combined aortic and mitral valve disease secondar to rheumatic fever. (a) Pre-operative film: markedly enlarged heart with plethora of the lung fields. (b) Post $\Omega$ operative chest radiograph 4 months after surgery indicating significant reduction of heart size. Both the aorti $\mathbb{B}$ and mitral lesions were corrected using Starr-Edwards prostheses. At present, 9 months after surgery, this patient has made good improvement. 

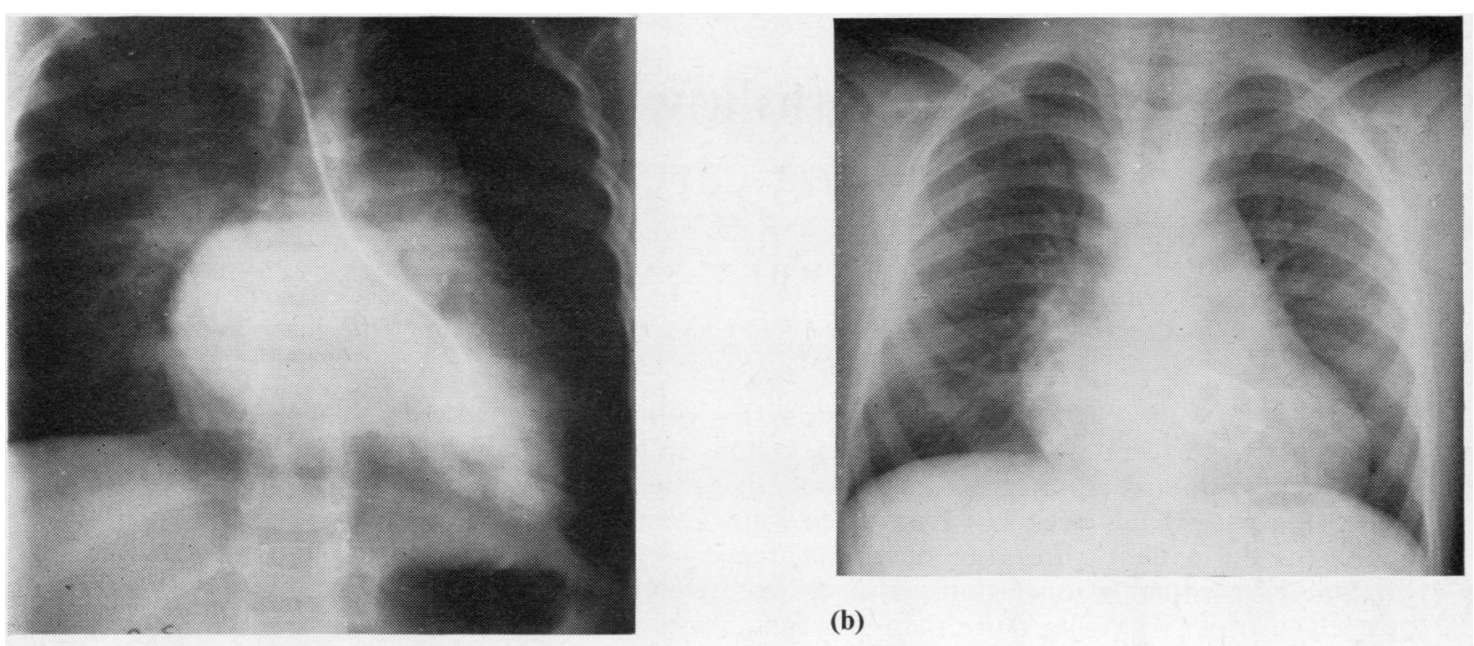

(b)

(a)

FIG. 6. Pre- and post-operative chest radiographs of a 3-year-old boy with severe mitral insufficiency due to Marfan's disease. (a) Pre-operative selective ventriculogram with tip of the catheter in the left ventricle. Contrast material is injected into the left ventricle and opacifies densely the enlarged left atrium. (b) Post-operative film: One year after insertion of Starr-Edwards ball valve to correct the mitral insufficiency.

course, a case of small aortic annulus might pose special technical problems and require a specially made prosthesis, which is today available.

The tricuspid valve is rarely affected at this age, and in the majority of cases does not require any attention; however, if a congenital lesion is present, such as Ebstein's anomaly or the A-V communis malformation, the treatment of choice in these circumstances may be valve replacement. In the single case in our group with Ebstein's anomaly, it was our impression that this was done too late (Gueron, Hirsch, Stern, Cohen, and Levy, 1966).

The question of later valve replacement and the fate of the prostheses currently used is a matter of a longer period of follow-up ; at present, however, the overall result has been encouraging and might justify a more aggressive approach toward this specific group of patients to whom many of us were reluctant to offer such definitive treatment as valve replacement. Of interest is the fact that in this period of follow-up no incidence of recurrent rheumatic fever was recorded. All the patients who had a previous history of rheumatic fever were placed under preventive antibiotic therapy.

\section{REFERENCES}

Bloodwell, R. D., Hallman, G. L., and Cooley, D. A. (1968). Cardiac valve replacement in children. Surgery, 63, 77.

Gueron, M., Hirsch, M., Stern, J., Cohen, W., and Levy, M. J. (1966). Familial Ebstein's anomaly with emphasis on the surgical treatment. Amer. J. Cardiol., 18. 105.

Levy, M. J., Varco, R. L., Lillehei, C. W., and Edwards, J. E. (1963). Mitral insufficiency in infants, children, and adolescents. $J$. thorac. cardiovasc. Surg., 45, 434.

- Vidne, B., and Lebinshon, S. (1969). Surgery for aortic valve: prosthesis and heterograft. Surgery, 66, 313.

Shahin, W., Eshkol, D., and Levy, M. J. (1969). Valve replacement for mitral insufficiency in an infant with Marfan's syndrome. $J$. pediat. Surg., 4, 350.

Vidne, B., and Levy, M. J. (1969). On the problem of thromboemboli related to heart valve prosthesis. A survey of 139 consecutive cases. Israel J. Med. Sci., 5, 395. 